Revista do SELL

v. $4, n^{\circ} .1$

ISSN: $1983-3873$

\title{
ANÁLISE DOS CLUSTERS DOS VERBOS HAVER E TER EM TEXTOS DOS SÉCULOS XIV, XV E XVI
}

\author{
CLUSTERS' ANALYSIS OF VERBS BE AND HAVE IN TEXTS OF CENTURIES XIV, XV \\ $A N D X V I$
}

\author{
Gabriele Cristine Carvalho \\ UFMG / IFMG
}

RESUMO: Neste trabalho, foram analisados os clusters dos verbos haver e ter em textos dos séculos XIV, XV e XVI. Foram utilizados o modelo teórico da Gramática Baseada no Uso, proposto por Bybee $(2006,2010)$, o modelo teórico-metodológico variacionista, para a análise dos dados, os estudos diacrônicos de Mattos e Silva (1992) sobre os verbos haver e ter e as discussões sobre verbos leves desenvolvidas por Perini (ms.). Obtiveramse 386 dados que foram separados e analisados manualmente. Os resultados da análise quantitativa mostraram que o verbo haver predomina sobre o verbo ter, mas há um aumento progressivo do verbo ter. A análise descritiva dos clusters mostrou que, no período analisado, haver e ter apresentam muitos clusters em comum e podem ser analisados como verbos leves.

PALAVRAS-CHAVE: cluster, análise quantitativa, verbo leve.

ABSTRACT: In this work, we analyzed the clusters of the verbs haver (there to be) and ter (have) in $14^{\text {th }}, 15^{\text {th }}$ and $16^{\text {th }}$ century texts. We used the theoretical model of the Usage Based Grammar, proposed by Bybee $(2006,2010)$, the variational theoreticmethodological model. For data analysis, we used the diachronic studies by Mattos e Silva (1992) about the verbs haver and ter and discussions about light verbs, developed by Perini (ms.). 386 data that were obtained were separated and analyzed manually. The results of quantitative analysis showed that the verb haver dominates over the verb ter, but there is an increasing progress of the verb to ter. The descriptive cluster analysis showed that, in this period, haver and ter have many clusters in common and these verbs can be analyzed as light verbs.

KEYWORDS: cluster, quantitative analysis, light verb.

\section{1- Introdução}

Este trabalho tem por objetivo analisar a variação dos verbos ter e haver, em textos dos séculos XIV, XV e XVI e fazer uma descrição dos seus clusters de exemplos. Para tanto, foram utilizados o modelo teórico da teoria da Gramática baseada no Uso, proposta por Bybee (2006, 2010), e o modelo teórico-metodológico variacionista para o tratamento dos dados. Além disso, foram utilizados os estudos de Mattos e Silva (1992) sobre os verbos ter e haver e as considerações sobre verbo leve, desenvolvidas por Perini (ms.). 


\section{Revista do SELL}

v. $4, n^{\circ} .1$

ISSN: $1983-3873$

Mattos e Silva (1992) já havia estudado a variação dos verbos haver e ter, em textos do século XIV e XV, em estruturas possessivas. Nos exemplos a seguir, retirados de Mattos de Silva (1992, p.91), observa-se a variação de ter e haver em estruturas que indicam posse.

(1) Ovelhas que el avia.

(2) Acharon huu homem terr huu carneiro.

Neste trabalho, além de se analisarem todos os contextos em que esses verbos ocorrem, realizou-se uma descrição do cluster desses verbos. Segundo Bybee (2006, 2010), os tokens semelhantes são armazenados juntos, formando cluster de exemplos (cf. seção 3). Como se verá a seguir, os verbos ter e haver são usados nos mesmos contextos e compartilham muitos clusters de exemplos. Observe-se, nestas ocorrências, que esses verbos coocorrem em sete contextos diferentes, no período destacado.

a) Posse abstrata: o complemento do verbo é um SN, representado por um substantivo abstrato.

(3)"E em nesto filharás vingança de mim, e teus filhos e parentes haveram prazer, e a minha alma será salva." (Mattoso, 1980, p. 208)

(4) "E isto medês [mesmo] faz nos cuidados dalgumas obras que the parecerem boas e virtuosas que se dispõem a eles assim destemperadamente, que não têm cuidado de comer, dormir, nem nem da folgança ordenada (...)" (D. Duarte, 1982, p. 38)

b) Posse material: o complemento do verbo é um SN, representado por um substantivo concreto.

(5) "E Alboazer Alboçadam jurou-Ihe por sa lei de Mafomede que lha nom daria por todo $o$ reino que ele havia, ca a tiinha esposada com el rei de Marrocos." (Mattoso, 1980, p. 205)

(6) "Uma [maneira de sentir inveja] por ver as cousas de vantagem a outro haver, de que Ihe não praz. A outra por ele não ter bem assim como queria." (D. Duarte, 1982, p. 83) 


\section{Revista do SELL}

v. $4, n^{\circ} .1$

ISSN: $1983-3873$

c) Existência: o verbo indica a existência de um ser.

(7) Há antrele mujtas palmas deque colhemos mujtos e boos palmjtos. (Cortesão, 1943, f. 11)

(8) "E oolharom por as chagas que tiinha e houverom por gram maravilha de lhe tanto poder durar a força, ca elas eram grandes e estavam em logares mortaes." (Mattoso, 1980, pág. 222)

d) Acontecimento: o verbo indica um acontecimento.

(9) "E preguntou se eram sabudos e certos aqueles a quem tais cousas aconticiam, ou se avinham ora a uns, ora a outros." (Abreu; Viana, s.d., p. 118)

(10) "E esto nom foi maravilha por assi teerem, ca i houve golpes que derom per cima dos // ombros que fenderom meetade dos corpos e as selas em que iam e gram parte dos cavalos, e outros talhavam per meio, (...)" (Mattoso, 1980, p. 221222)

e) Necessidade: o verbo sinaliza a necessidade de ocorrência de um evento.

(11) E nós, que havemos nosso padre eternal nos céus, pêra sempre duradoiro e esposo que nom há-de morrer (...) (Nunes, 1907, p.123)

(12) "E sobre tais fundamentos não têm de obrar para dar a execução, nem meter em proveitosa ordenança." (D. Duarte, 1982, p. 72)

f) Auxiliar: o verbo funciona como um auxiliar e virá acompanhado de um particípio passado. 


\section{Revista do SELL}

v. $4, n^{\circ} .1$

ISSN: $1983-3873$

(13) " $\mathrm{Ca}$, segundo tenho praticado, esta é a mais certa maneira da arte memorativa, ainda que bem sei como a outra muitas vezes presta em tempo de necessidade aos que a bem sabem, se têm razoadamente a natural." (D. Duarte, 1982, p. 36)

(14) Havia todavia pensado porque o ençarrara assi seu padre. (Abreu; Viana, s.d., p. 117)

f) Expressão idiomática: o cluster do verbo funciona como uma expressão idiomática ${ }^{1}$.

(15) "Rogo-te e peço que esta obra que em mim começaste, que te Plaza e tenhas por bem de ma leixares acabar." (Pereira, 1887, p. 126)

(16) "E ele respondeu que se havia por pior que ele. Disseram eles que tal palavra era contrafeita [errada], porque bem era vista quanta diferença dele ao outro era conhecida." (D. Duarte, 1982, p. 77)."

Destaque-se que a quantidade de contextos ilustrados pelos verbos permite propor que os verbos haver e ter apresentam uma perda de conteúdo semântico nesse período e é o complemento dos mesmos que frequentemente expressa o significado verbal. Assim, esses verbos podem ser analisados como verbos leves nos séculos XIV, XV e XVI.

\section{2- Trabalhos anteriores}

Nessa seção, serão apresentados o trabalho de Perini (ms.), que desenvolveu algumas considerações sobre os verbos leves e uma breve resenha dos estudos históricos de Mattos e Silva (1992) sobre os verbos ter e haver.

\footnotetext{
${ }^{1}$ Considera-se expressão idiomática uma construção que não é transparente, ou seja, uma expressão cujo significado não corresponde à soma de significados de cada um de seus elementos (Tagnin, 1989).
} 


\section{Revista do SELL}

v. $4, n^{\circ} .1$

ISSN: $1983-3873$

\section{1- Considerações de Perini sobre os verbos leves}

Vejamos, em primeiro lugar, as funções desempenhadas por um verbo pleno. Conforme Perini (ms.), um verbo pleno deve:

(a) especificar a natureza de um evento, estado, mudança de estado etc. (função semântica lexical);

(b) identificar um conjunto de papéis temáticos associados a seu significado (função temática);

(c) distribuir os papéis temáticos entre os diferentes complementos (função simbólica).

As funções destacadas acima não seriam integralmente cumpridas por um verbo leve. Observe-se o exemplo a seguir:

(17) José tem medo.

Nesse caso, pode-se dizer que o verbo ter especifica a natureza do evento (é um evento estativo), mas é difícil dizer que esse verbo sozinho projeta os papéis temáticos associados a seu significado e os distribui a diferentes complementos.

Além disso, conforme Trask (1992, p. 160 apud Perini, ms.), verbo leve pode ser definido como "um verbo com pouco ou nenhum conteúdo semântico próprio, que se combina com um objeto direto (geralmente indefinido) [...] que expressa um significado verbal." No caso da construção ter medo, observe-se que o verbo ter apresenta pouco conteúdo semântico e o significado da construção é expresso principalmente pelo substantivo medo.

\section{2- Mattos e Silva: uma análise histórica dos verbos haver e ter}

Mattos e Silva (1992) estudou a variação de ter e haver nas estruturas possessivas. A autora define três tipos semânticos dessas estruturas, de acordo com o complemento que acompanha esses verbos:

- qualidades inerentes, não transferíveis, tais como características ou estados físicos do possuidor, sujeito da frase (abrev. $\underline{\mathrm{Q}}$ ); 


\section{Revista do SELL \\ v. $4, n^{\circ} .1$ \\ ISSN: $1983-3873$}

- qualidades adquiríveis imateriais: morais, espirituais, intelectuais, afetivas, sociais (abrev. $\underline{\text { Al)}) ; ~}$

- objetos materiais adquiríveis, externos ao possuidor (abrev. $\underline{\mathrm{AM}}$ ). (Mattos e Silva, 1992, p.90).

Mattos e Silva (1992) salienta que, nos dados do século XIV, as estruturas do tipo QI ocorriam exclusivamente com o verbo haver, já nas estruturas do tipo Al e AM, esses verbos pareciam variar. Os dados do século XIV mostraram também que as estruturas do tipo Al ocorriam predominantemente com o verbo haver (80\%) e as estruturas do tipo AM ocorriam preferencialmente com o verbo ter $(82 \%)$. A análise dos itens lexicais que compunham essas estruturas mostrou que o verbo ter, nas estruturas do tipo Al, só se apresentou com o complemento fé, ao passo que o verbo haver vinha seguido por mais de 20 itens lexicais diferentes como complemento. Então, a autora declara que a variação ocorria de fato com as estruturas do tipo AM.

É interessante observar que a variação dos verbos ter e haver começa a ser verificada com os três tipos de complemento nos textos escritos entre 1418-1442, mas, nas estruturas do tipo QI, há uma predominância de haver sobre ter. Nos textos escritos entre 1468-1477, a variação continua, mas a situação se inverte, a variante nova predomina em todos os tipos de estruturas.

Neste trabalho, as estruturas classificadas por Mattos e Silva como Al, são classificadas como "posse abstrata" e as do tipo AM, como "posse material". Não foram encontradas as estruturas classificadas como Ql por Mattos e Silva. Além disso, consideram-se todos os contextos em que esses verbos ocorrem e não somente aqueles que denotam posse.

\section{3- Referencial teórico: a Gramática Baseada no Uso}

Na perspectiva baseada no uso da língua, defende-se que a experiência do indivíduo com a língua pode afetar sua representação mental. Segundo Bybee (2006, p.711), a gramática pode ser entendida como "a organização cognitiva da experiência de alguém com a língua". Isso significa que a frequência de uso de determinadas construções pode afetar sua representação e é por isso que nós reconhecemos, por exemplo, quais construções são convencionalizadas e quais não são. Nessa teoria, a 


\section{Revista do SELL}

v. $4, n^{\circ} .1$

ISSN: $1983-3873$

língua é tratada como um fenômeno que apresenta ao mesmo tempo uma regularidade de estrutura e uma considerável variação em todos os níveis.

Em relação ao armazenamento dos dados, destaque-se que os tokens de experiência são organizados em uma rede, em que novos tokens de experiência, quando idênticos, são armazenados juntos com o modelo existente, fortalecendo-o. Tokens que são semelhantes aos existentes são armazenados próximos a eles, formando clusters. Segundo Bybee (2006), o mesmo ocorreria com as construções, i. e., construções que compartilham uma semelhança formal e uma coerência semântica são armazenadas próximas umas às outras (cf. seção 6.3.1).

Para entender como funciona a representação das construções na teoria dos exemplares, é necessário ter em mente que as construções são parcialmente esquemáticas, apresentando partes fixas e partes abertas. Quando um novo token da parte fixa da construção é ouvida por um usuário da língua, esse token fortalecerá o modelo anterior. Contudo, se um novo token ocorre na parte esquemática da construção e esse é semelhante a um modelo anterior, será formada uma nova categoria.

No presente trabalho, faz-se uma descrição e classificação dos clusters dos verbos ter e haver. Nesse caso, como se verá, algumas construções são parcialmente esquemáticas, já que a parte fixa é formada pelo verbo ter ou pelo verbo haver e a parte aberta se constitui por uma vasta gama de substantivos abstratos, concretos, por um sintagma preposicional ou por uma oração. Outras construções podem ocorrer com os dois verbos. Nesse caso, as construções são mais esquemáticas.

\section{4- Metodologia}

A metodologia da coleta e análise quantitativa dos dados orientou-se pelo modelo variacionista laboviano, já que as evidências fornecidas pelos estudos de Mattos e Silva (1992) atestam que os verbos ter e haver, nos séculos XIV e XV, variam em construções que apresentam o traço semântico de posse. Nesta pesquisa, foram selecionadas todas as ocorrências que exibiram os verbos ter e haver para que se pudesse analisar a distribuição desses verbos em textos dos séculos XIV, XV e XVI, além de se fazer uma descrição e classificação dos seus clusters de exemplos.

Obtiveram-se 386 dados que foram separados, classificados e quantificados manualmente. Após a análise quantitativa, realizou-se uma análise qualitativa dos dados. 


\section{Revista do SELL}

v. $4, n^{\circ} .1$

ISSN: $1983-3873$

Os textos escolhidos para a análise foram:

\section{Século XIV}

MATTOSO, J. (Ed.). Portugaliae Monumenta Histórica; a saeculo octavo post quintumdecimun iussu academiae scientiarum olisiponensis edita. Livro de linhagens do conde D. Pedro. Lisboa: Academia das Ciências, 1980. Volume II/I. p. 204-222, 295-299, 393-396. (Banco de textos (FALE/UFMG) para pesquisa em Linguística Histórica.

NUNES, J.J. Vida de Santa Pelágia (Revista Lusitana, vol. X, 1907). In: FERREIRA, M. E. T. (Org.). Poesia e prosa medievais. Biblioteca Ulisseia de autores portugueses, s.d.

PEREIRA, E. (Ed.). Vida de Santo Aleixo (Revista Lusitana, vol. I, 1887). In: FERREIRA, M. E. T. (Org.). Poesia e prosa medievais. Biblioteca Ulisseia de autores portugueses, s.d.

ABREU, G. de V. \& VIANA, A. R. G. Lenda de Barlaão e Josafá (História e Memória da Academia Real de Ciências, Tomo VII, Parte II, Memória I). In: FERREIRA, M. E. T. (Org.). Poesia e prosa medievais. Biblioteca Ulisseia de autores portugueses, s.d.

\section{Século XV}

D. DUARTE. Leal conselheiro. Lisboa: Imprensa Nacional - Casa da Moeda, 1982. p. 21-106.

\section{Século XVI}

CORTESÃO, Jaime. A carta de Pero Vaz de Caminha. Rio de Janeiro: Livros de Portugal, 1943. p. 135-187.

\section{5- Análise dos dados}

Esta seção divide-se em duas partes. Na primeira parte, serão descritos os clusters dos verbos haver e ter e serão feitas considerações sobre essas descrições. Na segunda parte, será realizada uma análise quantitativa e qualitativa dos verbos haver e ter por período. 


\section{1- Descrição dos clusters dos verbos ter e haver}

\subsection{1- Descrição do cluster do verbo haver}

Constatou-se que o verbo haver apresenta-se em 7 contextos diferentes e possui 14 tipos diferentes de clusters, nesse período. Vejamos a distribuição do verbo haver no gráfico a seguir.

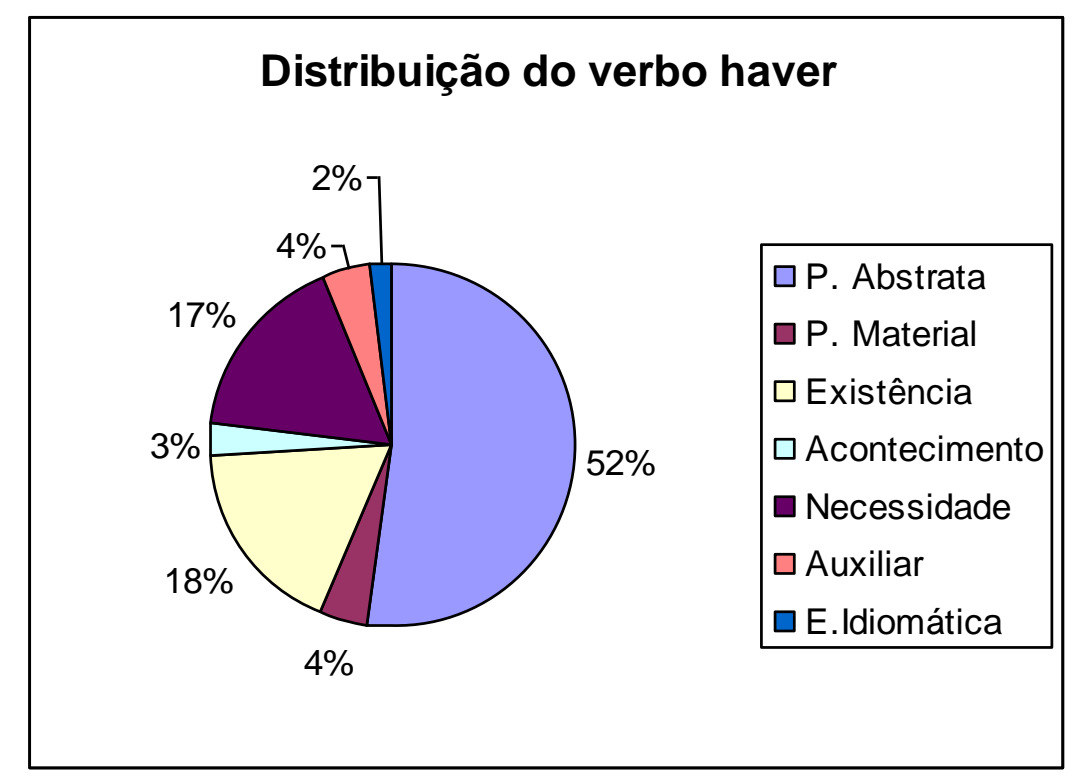

Gráfico 1- Distribuição do verbo haver por contexto.

Como se pode ver, $52 \%$ das ocorrências desse verbo foram de posse abstrata, $4 \%$ de posse concreta, $18 \%$ de existência, 3\% de acontecimento, $17 \%$ representam necessidade, em $4 \%$ dos casos o verbo haver foi usado como auxiliar e em $2 \%$, fazendo parte de uma expressão idiomática. Apesar de o verbo haver não se distribuir de forma muito desigual no período analisado, contata-se que esse verbo ocorre preferencialmente em construções que denotam posse abstrata, existência e necessidade, respectivamente.

Vejamos os clusters que ocorreram dentro de cada contexto.

\section{Posse abstrata :}

A) Haver + SN (substantivo abstrato) 


\section{Revista do SELL \\ v. $4, n^{\circ} .1$ \\ ISSN: $1983-3873$}

Nesse cluster, o verbo haver esteve acompanhado pelos seguintes substantivos abstratos: acolhimento, alma, amor, avisamento, bondade, cobro, conclusão, concordância, conhecimento, conselho, consideração, contrariedade, contrição, corregimento, cuidado, cura, deleito/deleitação, desejo, desonra, desprazer, desprezo, discrição, emenda, entendimento, ensinança, espanto, esperança, exemplo, experiência, fala, fim, fundamento, galardão, gança, glória, graça, guerra, honra, hospício (hospedagem), inveja, juízo, lembrança/lembramento, lide, limpeza, medo, obrigação, ódio, ordenada (ordem), paixão, pena, pousada (hospedagem), plazer/prazer, poderio, proveito, riqueza, saber, sanha, saúde, sentido, sinais, tempo, temor, tenção, tristeza, vencimento (vitórias), ventura, vergonha, vida, vingança, virtude, vista, vitória.

B) Haver + SP (preposição + substantivo abstrato)

O verbo haver, nesse cluster, ocorreu com sintagmas preposicionais encabeçados pelas preposições com, de e por, a saber: de costume, com avisamentos, com conselho, com razão, por estranho, por maravilha.

C) Haver+ SN (pessoa)

O verbo haver vem acompanhado de um substantivo comum que designa uma pessoa, como: conselheiro, filho, mulher, nosso padre eternal nos céus, rei.

Faz-se necessário observar que, nesse contexto, o verbo haver não está indicando existência, um indício é que o verbo não é impessoal.

D) Haver + SN (nome) + substantivo próprio

Nesse caso, o verbo haver vem seguido do substantivo nome e de um substantivo próprio. Pode-se dizer que a construção haver nome substitui o verbo chamar-se, que quase não é utilizado nesse período. 


\section{Revista do SELL}

v. $4, n^{\circ} .1$

ISSN: $1983-3873$

\section{Posse material :}
A) Haver+ $\mathrm{SN}$ (substantivo concreto/ pronome indefinido retomando um substantivo concreto)

Nesse contexto, o verbo haver é utilizado com o sentido de possuir um bem. Ressalte-se que, nesse uso, muitas vezes o complemento do verbo ficou subentendido. Os seguintes complementos ocorreram com esse verbo denotanto posse material : bens, quanto, reino, tudo.

B) Haver +SP (preposição+substantivo concreto) $+\mathrm{SN}$ (substantivo concreto)

Nesse caso, o verbo haver é bitransitivo, apresentando um sintagma preposicional encabeçado pela preposição de, que recebe o papel temático de fonte, e um sintagma nominal, que indica o bem a ser transferido, recebendo o papel temático de meta. Obtevese apenas uma ocorrência desse cluster.

\section{Existência}

$$
\text { Haver + SN }
$$

O verbo haver, denotando existência, foi acompanhado dos substantivos: arte, aldeia, aves, casa, catadura, coisa, consciência, conselho, escolha, força, geração, homem, homezio, infiel, inhame, irmão, juízo, míngua, mulher, palma, parte, pecados, porta, prata, quanto, rei, remédio, semente, tanto, tempo, vida.

\section{Acontecimento}

\section{A) Haver+SN}

Obtiveram-se poucas ocorrências desse cluster, sendo que, em alguns casos, o verbo haver era impessoal e, em uma ocorrência, concordou com o SN. Além disso, 


\section{Revista do SELL}

v. $4, n^{\circ} .1$

ISSN: $1983-3873$

ressalte-se que esse SN poderia estar subtendido, já que era facilmente recuperável pelo contexto.

Para indicar acontecimento, o verbo haver apresentou-se com os SN's: batalha, tudo e coisa.

B) Haver+ oração

Nesse cluster, foram registradas duas ocorrências, em que o verbo haver foi seguido destas orações: $\mathrm{SN}+$ a levar e sintagma adverbial + ter pousada.

\section{Necessidade}

\section{A) Haver+Preposição+VP}

Para indicar necessidade, o verbo haver, no período analisado, vem seguido das

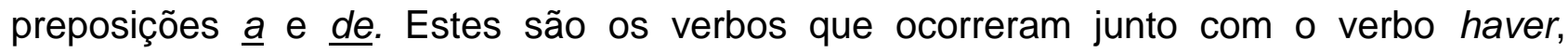
indicando necessidade: acabar, andar, considerar, dar, durar, empacho, entrar, enviar, escrever, fazer, falecer, ficar, guardar, haver, julgar, lidar, mandar, morrer, obrar, pagar, passar, poer, proceder, ser, trabalhar, ver, vir. Destaque-se que a preposição a ocorreu somente com os verbos lidar, fazer e mandar.

B) Haver+ VP

Obtiveram-se três ocorrências do verbo haver seguido diretamente por um VP. Nesse caso, o verbo haver apresentou-se com os verbos alegrar, fazer e ser.

\section{Auxiliar}

Haver +particípio passado

O verbo haver ocorreu com os particípios dos verbos: acabar, aficar, costumar, errar, escrever, fazer, governar, partir, pensar. Destaque-se que somente em uma 


\section{Revista do SELL}

v. $4, n^{\circ} .1$

ISSN: $1983-3873$

ocorrência o particípio passado funcionou como adjetivo, concordando em gênero e número com o substantivo a que se referia ${ }^{2}$.

\section{Expressão idiomática}
A) Haver+ SP

Nesse cluster, o verbo haver é seguido por um SP, constituído pela preposição por + adjetivo/advérbio. O adjetivo que ocorreu nesse cluster foi boa e os advérbios foram bem e pior.
B) Haver+ lugar

Identificou-se também o cluster formado por haver seguido pelo substantivo lugar, significando ocorrer.

\subsection{2- Descrição do cluster do verbo ter}

O verbo ter apresenta-se em 8 contextos diferentes, e possui 13 tipos diferentes de clusters, no período analisado, como se observa a seguir.

\footnotetext{
${ }^{2}$ Mattos e Silva (1992) considera os verbos ter e haver verbos principais e não auxiliares, quando o adjetivo-PP é um constituinte do SN complemento direto. Neste trabalho, obtiveram-se poucas ocorrências de haver e ter + PP, de forma que não se fez uma separação das ocorrências em que, nesse contexto, o PP funcionaria como verbo principal ou como parte do SN complemento direto. Contudo, para maiores considerações é necessário refinar a análise.
} 


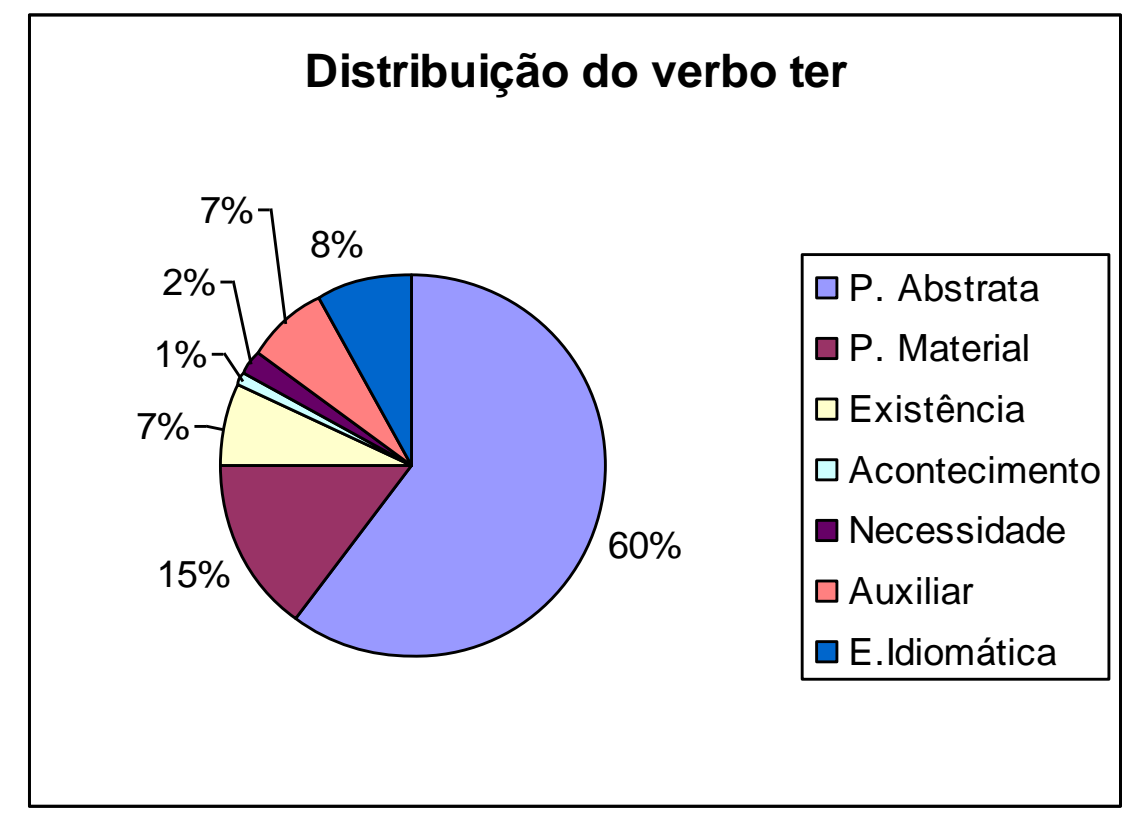

Gráfico 2- Distribuição do verbo ter por contexto.

O gráfico 2 permite constatar que o verbo ter indica preferencialmente posse abstrata $(60 \%)$, mas também há um grande número de ocorrências em que o verbo denota necessidade (15\%), funciona como expressão idiomática (8\%) ou como auxiliar (7\%) e indica existência (7\%). Verifica-se também um pequeno número de ocorrências em que o verbo ter indica posse material (2\%) e acontecimento (1\%).

A seguir apresentam-se os tipos de cluster por contexto.

\section{Posse abstrata :}

Ter+ SN (substantivo abstrato)

Assim como o verbo haver, o verbo ter indica preferencialmente posse abstrata. No período analisado, esse verbo vem acompanhado destes substantivos abstratos: acatamento, amor, arte (da memória), cargo, caridade, comum, conhecimento, cousa (não material), crença, cuidado, diferença, entender, estado (classe social), fama, fundamento, graça, intenção, jeito, lembrança, longanidade, maneira, medo, mercê, misericórdia, modo, nascimento, ofício, parte (de bem), paz, piedade, poder, pousada (hospedagem), prática, prazer, razão, regimento, sanha, tenção, vantagem, vergonha, virtude, vontade, VOZ. 


\section{Revista do SELL}

v. $4, n^{\circ} .1$

ISSN: $1983-3873$

\section{Posse material :}

A) Ter+ SP (preposição +substantivo concreto)+ SN (substantivo concreto)

Nesse caso, o verbo ter é bitransitivo, apresentando um sintagma preposicional, que recebe o papel temático de fonte e um sintagma nominal, que recebe o papel temático de meta. Nesse sentido, atualmente usamos o verbo obter. Registrou-se apenas uma ocorrência desse cluster, em que o SP era del dom Rodrigo Gomez de Trastamar e o SN era o condado de Trastamar.

B) Ter+SN (substantivo concreto)

Nesse cluster, o verbo ter ocorreu com os seguintes complementos: bem, bico, cousa (material), rabo, rede, tudo (material), vergonha (órgão sexual), vianda. ${ }^{3}$

C) Ter+SP (preposição+substantivo concreto)

É interessante observar, que, nesse cluster, o SP sempre se posiciona antes do verbo ter (del tinha), significando que alguém tinha parte de alguma coisa. Parece que, nesse caso, esse cluster foi substituído, posteriormente, pelo verbo deter.

\section{Existência}

Ter+SN

Estes substantivos apresentam-se com o verbo ter, indicando existência: água, chaga, diferença, maneira, porta, ribeira.

\section{Acontecimento}

Ter+SN (subentendido)

\footnotetext{
${ }^{3}$ Para uma análise mais refinada, posteriormente, será necessário separar os SN's que indicam posse alienável daqueles que indicam posse inalienável.
} 


\section{Revista do SELL}

v. $4, n^{\circ} .1$

ISSN: $1983-3873$

Encontrou-se apenas uma ocorrência do verbo ter indicando acontecimento. Mesmo assim, o argumento desse verbo estava subtendido.

\section{Necessidade}

\section{Ter+Preposição+VP}

Obtiveram-se apenas duas construções com esse cluster, sendo que, nos dois casos, a preposição de ligava o verbo ter aos verbos dizer e obrar.

\section{Expressão idiomática}
A) Ter+ SP

Nesse cluster, o verbo ter é seguido por um sintagma preposicional, constituído pela preposição por + advérbio. Os advérbios que ocorreram nessa expressão idiomática foram: bem, mal, tal.

B) $T e r+S P(e m+S N)$

O verbo ter apresentou-se em três tipos de construções nesse cluster, formando a expressão ter em conta, ter em par de morte e ter neste propósito.

\section{Outro uso do verbo ter:}

Ter+complementizador (que)+oração

Nesse caso, o verbo ter significa entender e sempre vem acompanhado por uma oração subordinada substantiva objetiva direta, encabeçada pelo complementizador que. 


\section{Revista do SELL}

v. $4, n^{\circ} .1$

ISSN: $1983-3873$

\subsection{3- Considerações sobre a descrição de clusters}

A descrição dos clusters dos verbos ter e haver permite analisar esses verbos como verbos leves, pois, como eles podem se apresentar em sete contextos diferentes ${ }^{4}$, dividindo-se, nesses contextos, de forma não muito desigual (como atestam os gráficos 1 e 2), parece haver uma perda de conteúdo semântico dos verbos, podendo-se aventar a hipótese de que o complemento desses verbos (seja um SN, SP ou uma oração) determina o sentido dos mesmos.

É interessante observar também que, em quase todos os casos, ter e haver compartilham o mesmo cluster, i. e., nesse caso, o cluster teria uma parte totalmente aberta e uma parte parcialmente aberta, já que poderia ocorrer com os dois verbos. Isso ocorre no contexto de posse abstrata, no cluster haver/ter+SN (substantivo concreto); no contexto de posse material, nos clusters haver/ter+SP+SN e haver/ter+SN; no contexto de existência, no cluster haver/ter+SN; ao indicar acontecimento, no cluster haver/ter+SN (sendo que o SN pode estar subentendido); para indicar necessidade, compartilham o cluster haver/ter+preposição+VP; funcionando como auxiliar, no cluster haver/ter+particípio passado; em expressões idiomáticas, no cluster haver/ter+SP.

Ao analisar o contexto de posse abstrata, deve-se levar em consideração que apenas treze substantivos ${ }^{5}$ podem ocorrer com os dois verbos. Isso nos conduz à reflexão de que, no período analisado ou em um período anterior, havia um cluster dos substantivos que ocorriam com o verbo haver e outro cluster com os substantivos que ocorriam com o verbo ter. Pode-se considerar a hipótese que, posteriormente, esses clusters se fundiram.

Em relação aos outros contextos, é difícil tecer maiores considerações, já que o número de ocorrências é restrito. Contudo, como o verbo haver apresenta mais ocorrências em quase todos os contextos analisados, pode-se propor que os clusters desse verbo serviram de base analógica para a entrada do verbo ter. Somente no contexto de posse material, o cluster do verbo ter parece ter servido de base analógica para a entrada do verbo haver. Segundo Bybee (2006, 2010), os clusters de exemplos

\footnotetext{
${ }^{4} \mathrm{O}$ verbo ter apresenta-se em oito contextos, mas compartilha sete contextos com o verbo haver. Assim, para uma análise comparativa, esse uso foi desconsiderado.

${ }^{5}$ Estes são os substantivos que ocorrem com ambos os verbos, no contexto de posse abstrata: amor, conhecimento, cuidado, fundamento, graça, lembrança, medo, pousada, prazer, sanha, tenção, vergonha e virtude.
} 


\section{Revista do SELL}

v. $4, n^{\circ} .1$

ISSN: $1983-3873$

possuem membros centrais (os mais frequentes) e membros periféricos (os menos frequentes). Nessa teoria, os membros centrais servem de base analógica para a entrada de novos itens lexicais nas construções existentes.

\section{2- Análise quantitativo-qualitativa dos verbos haver e ter}

A análise dos dados permite concluir que, em quase todos os contextos e períodos analisados, há uma predominância do verbo haver sobre o verbo ter. O verbo ter predomina ligeiramente apenas nas construções que indicam posse material e nas expressões idiomáticas. Observe-se a tabela 1 a seguir.

Tabela 1- Frequência dos verbos haver e ter por contexto e por período.

\begin{tabular}{|c|c|c|c|c|c|}
\hline \multicolumn{2}{|l|}{ Construções } & \multicolumn{2}{|c|}{ Haver } & \multicolumn{2}{|c|}{ Ter } \\
\hline & Séc. & $\mathrm{N}^{\circ}$ & $\%$ & $\mathrm{~N}^{\circ}$ & $\%$ \\
\hline \multirow[t]{3}{*}{ Posse abstrata } & XIV & 40 & 83 & 8 & 17 \\
\hline & $\mathrm{XV}$ & 90 & 60 & 59 & 40 \\
\hline & $\mathrm{XVI}$ & 9 & 53 & 8 & 47 \\
\hline \multirow[t]{3}{*}{ Posse material } & XIV & 5 & 38 & 8 & 62 \\
\hline & $\mathrm{XV}$ & 5 & 56 & 4 & 44 \\
\hline & $\mathrm{XVI}$ & 0 & 0 & 6 & 100 \\
\hline \multirow[t]{3}{*}{ Existência } & XIV & 20 & 91 & 2 & 9 \\
\hline & $\mathrm{XV}$ & 16 & 84 & 3 & 16 \\
\hline & $\mathrm{XVI}$ & 12 & 80 & 3 & 20 \\
\hline \multirow[t]{3}{*}{ Acontecimento } & XIV & 6 & 86 & 1 & 14 \\
\hline & $\mathrm{XV}$ & 0 & - & 0 & - \\
\hline & $\mathrm{XVI}$ & 1 & 100 & 0 & 0 \\
\hline \multirow[t]{3}{*}{ Necessidade } & XIV & 21 & 100 & 0 & 0 \\
\hline & $\mathrm{XV}$ & 16 & 94 & 1 & 6 \\
\hline & $\mathrm{XVI}$ & 8 & 89 & 1 & 11 \\
\hline \multirow[t]{3}{*}{ Auxiliar } & XIV & 7 & 70 & 3 & 30 \\
\hline & $\mathrm{XV}$ & 3 & 43 & 4 & 57 \\
\hline & $\mathrm{XVI}$ & 0 & 0 & 1 & 100 \\
\hline \multirow[t]{3}{*}{ Expressão idiomática } & XIV & 0 & 0 & 4 & 100 \\
\hline & $\mathrm{XV}$ & 4 & 40 & 6 & 60 \\
\hline & $\mathrm{XVI}$ & 1 & 100 & 0 & 0 \\
\hline
\end{tabular}




\section{Revista do SELL}

v. $4, n^{\circ} .1$

ISSN: $1983-3873$

A partir de uma análise mais cuidadosa da tabela 1, verifica-se que há um aumento progressivo das construções com o verbo ter e uma redução das construções com o verbo haver nesse período. Esse resultado corrobora a análise de Mattos e Silva (1992). Entretanto, os dados da autora mostraram que a variante inovadora predominava em todas as estruturas possessivas, no final do século XV. Mas, na presente pesquisa, no século $\mathrm{XV}$, o verbo haver ainda predomina nesse tipo de estrutura. No século XVI, verifica-se que há um equilíbrio entre os dois verbos no contexto de posse abstrata e que o verbo ter predomina sobre haver no contexto de posse material.

$\mathrm{Na}$ tabela 2, pode-se constatar que, considerando a totalidade dos dados, o verbo haver representa mais da metade dos dados analisados. Vejamos os dados dessa tabela.

Tabela 2- Frequência dos verbos haver e ter em textos dos séculos XIV, XV e XVI.

\begin{tabular}{|l|l|l|}
\hline \multirow{2}{*}{ Verbos } & \multicolumn{2}{|l|}{ Totalidade dos dados } \\
\cline { 2 - 3 } & $\mathrm{N}^{\circ}$ & $\%$ \\
\hline Haver & 264 & 68 \\
\hline Ter & 122 & 32 \\
\hline Total & 386 & 100 \\
\hline
\end{tabular}

\section{6- Considerações finais}

A partir da análise dos dados, verificou-se que os verbos ter e haver podem ser considerados leves, pois, como eles se apresentaram em muitos contextos diferentes, pode-se levantar a hipótese de que houve uma perda de conteúdo semânticos dos mesmos, no período analisado, e que o complemento desses verbos passou a determinar o seu sentido. A análise quantitativa permitiu verificar que o verbo haver predominou sobre o verbo ter em quase todos os contextos do período examinado, mas verificou-se um aumento das construções com o verbo ter e uma redução do uso do verbo haver. A descrição dos clusters dos verbos mostrou que eles compartilham muitos clusters no período. Como o verbo haver apresenta um número superior de ocorrências em quase todos os contextos, aventou-se a hipótese de que esse verbo serviu de base analógica para a entrada do verbo ter nos clusters em que compartilham. Apenas nos contextos de posse material, é possível propor que ter tenha servido de base analógica para o verbo 


\section{Revista do SELL}

v. $4, n^{\circ} .1$

ISSN: $1983-3873$

haver; já que, nesse contexto, o verbo ter apresenta mais ocorrências do que o verbo haver.

\section{Referências bibliográficas}

BYBEE, Joan. From usage to grammar: the mind's response to repetition. Language, 82, 711-733, 2006.

BYBEE, Joan. Language, usage and cognition. Cambridge: Cambridge University Press, 2010.

MATOS E SILVA, Rosa Virgínia. Caminhos de mudanças sintático-semânticas no português arcaico. Revista de Estudo da Linguagem. Belo Horizonte: Faculdade de Letras da UFMG, ano1, v.1, p. 85-99, jul./dez. 1992.

PERINI, Mário A. (ms.) O papel temático: relação cognitiva e instrumento de descrição.

TAGNIN, S. O. Expressões idiomáticas e convencionais. São Paulo: Ática, 1989. 